\title{
Nifuroxazide prompts antitumor immune response of TCL-loaded DC in mice with orthotopically-implanted hepatocarcinoma
}

\author{
TIESUO ZHAO ${ }^{1,3,4,6^{*}}$, HUIJIE JIA ${ }^{5 *}$, QIAN CHENG ${ }^{2}$, YALI XIAO ${ }^{1}$, MINMING LI $^{1}$, WENJING REN ${ }^{6}$, \\ CHEN LI $^{1}$, YUCHEN FENG ${ }^{1}$, ZHIWEI FENG ${ }^{1}$, HUI WANG ${ }^{3,4}$ and JUNNIAN ZHENG ${ }^{2}$ \\ ${ }^{1}$ Department of Immunology, Xinxiang Medical University, Xinxiang, Henan 453003; ${ }^{2}$ Jiangsu Key Laboratory of \\ Biological Cancer Therapy, Xuzhou Medical College, Xuzhou, Jiangsu 221002; ${ }^{3}$ Research Center for Immunology, \\ School of Basic Medical Sciences, Xinxiang Medical University; ${ }^{4}$ Henan Collaborative Innovation Center of \\ Molecular Diagnosis and Laboratory Medicine, Xinxiang Medical University; ${ }^{5}$ Department of Pathology, \\ Xinxiang Medical University; ${ }^{6}$ Department of Dermatology, The First Affiliated Hospital \\ of Xinxiang Medical University, Xinxiang, Henan 453003, P.R. China
}

Received October 28, 2016; Accepted April 13, 2017

DOI: $10.3892 /$ or.2017.5629

\begin{abstract}
Hepatocellular carcinoma (HCC) is a highly aggressive malignancy with a poor prognosis and high mortality. At present, vaccination with tumor cell lysate (TCL) loaded dendritic cells (DC) has been shown to be an effective therapy against HCC. However, the ability of promoting the specific $\mathrm{T}$ cell immune response is rather weak, influencing the antitumor response. Thus, it is necessary to find a strategy to improve the antitumor effect of TCL-loaded DC. Activation of signal transducer and activator of transcription 3 (STAT3) significantly inhibits antitumor immune response and DC maturity. Nifuroxazide, an antidiarrheal agent, has been proved to directly inhibit STAT3 activation. Thus, we investigated whether nifuroxazide could improve the antitumor immune response in mice vaccinated with TCL-loaded DC. The study provides the theoretical and experimental basis for developing an effective adjuvant for DC vaccine to treat $\mathrm{HCC}$.
\end{abstract}

Correspondence to: Professor Junnian Zheng, Jiangsu Key Laboratory of Biological Cancer Therapy, Xuzhou Medical College, Xuzhou, Jiangsu 221002, P.R. China

E-mail: jnzheng@xzhmu.edu.cn

Professor Hui Wang, Research Center for Immunology, School of Basic Medical Sciences, Xinxiang Medical University, Xinxiang, Henan 453003, P.R. China

E-mail: wanghui@xxmu.edu.cn

*Contributed equally

Abbreviations: HCC, hepatocellular carcinoma; TCL, tumor cell lysate; DC, dendritic cells; STAT3, signal transducer and activator of transcription 3; NK, natural killer

Key words: HCC, nifuroxazide, STAT3, TCL-loaded DC, antitumor immune response
Our results showed that the administration of nifuroxazide and DC-loaded TCL could significantly improve the survival rate, inhibit the tumor growth, and prompt the antitumor immune responses in mice with orthotopically implanted hepatocarcinomas, thus, possibly providing a new combination strategy to treat HCC.

\section{Introduction}

HCC is one of the most common malignancies worldwide, with a rapidly progressive clinical course (1). Patients with advanced HCC have an average life span of just a few months (2). At present, progress in the early diagnosis and treatment of HCC have increased the mean survival time, but the prognosis is still poor and novel therapeutic strategies are urgently needed (3). As known, the antitumor immune response is functionally impaired in HCC patients and the function of T cell is inhibited $(4,5)$. Thus, it is important to develop a treatment method to enhance the immune response in HCC patients.

Since found in 1973, dendritic cells (DC) pulsed with tumor-associated antigens have been applied as a therapeutic vaccine to tumor patients and they elicited an antitumor immune response (6,7). In addition, DC loaded with tumor cell lysate (TCL), prepared by the artificial lysis of tumor cells, significantly inhibited tumor growth, increased the survival of tumor-born mice and strengthened antitumor cytotoxic activity (8-10). However, it was reported that the application of TCL-loaded DC only elicited weak T cell responses (9). Furthermore, in tumor patients, most DCs are immature cells that do not express costimulatory signals required to promote T cell development.

It was demonstrated that the activation of signal transducer and activator of transcription 3 (STAT3) inhibits DC maturity $(11,12)$. The STATs are related to tumorigenesis and tumor progression, and STAT3 belongs to an important member of the STAT family that is excessively activated in many tumors, including hematological malignancies and solid malignancies (13). The abnormal expression of STAT3 in tumor tissues 
leads to tumor cell proliferation, suppression of cell apoptosis and impaired host antitumor immunity $(14,15)$. Thus, blocking STAT3 activation might have antitumor effects that inhibit the growth of human HCC cells including HepG2, PLC/PRF/5 and $\mathrm{H} 7402$ and strengthen the function of natural killer (NK) cells in a mouse model of HCC $(11,12)$. Therefore, it is important to develop a new, safer and more effective agent to inhibit the activation of STAT3, which might be applied to treat the HCC patients in the clinic. Nifuroxazide directly inhibited STAT3 thereby inhibiting the survival of multiple myeloma cells (16). Recently, nifuroxazide was also reported to induce apoptosis of breast cancer cells and inhibit pulmonary metastasis in a breast cancer model (17).

Thus, in this study, we observed the effect of combining nifuroxazide and DC pulsed with TCL on the survival rate and lymphocyte infiltration in tumor tissues of an orthotopically implanted hepatocarcinoma model. We found that the combination applied of nifuroxazide and DC pulsed with TCL improved the survival rate, inhibited the tumor growth, but also increased the $\mathrm{CD}^{+}$and $\mathrm{CD}^{+} \mathrm{T}$ cell infiltration in tumor tissues.

\section{Materials and methods}

Reagents and antibodies. Nifuroxazide was purchased from Shanghai Seebio Biotech, Inc and was preserved at $20 \mathrm{mg} / \mathrm{ml}$ solution in dimethyl sulfoxide (DMSO) and stored at $-20^{\circ} \mathrm{C}$. The cytokines of granulocyte-macrophage colony-stimulating factor (GM-CSF), interleukin (IL)-4 and tumor necrosis factor (TNF)- $\alpha$ were purchased from PeproTech Inc. (Rocky Hill, NJ, USA).

Mice. Male C57BL/6 mice, aged 6-8 weeks, were purchased from Vital River Laboratory Animal Technology Co. Ltd. (Beijing, China). All the mice were maintained at $22 \pm 2^{\circ} \mathrm{C}$ within pathogen-free conditions according to the Care and Use of Laboratory Animals of the National Institute of Health Guide.

Cell culture. Human HepG2 cells and the mouse hepatoma cell line H22 were obtained from Professor Xuejian Zhao (Department of Pathophysiology, Prostate Diseases Prevention and Treatment Research Centre, Norman Bethune College of Medicine, Jilin University, Changchun, China). All the cells were propagated in RPMI-1640 media supplemented with $10 \%$ heat-inactivated fetal bovine serum (FBS, Gibco) and cultured in a $5 \% \mathrm{CO}_{2}$ humidified incubator at $37^{\circ} \mathrm{C}$.

Cell viability assay. HepG2 cells were plated into 96-well flat-bottom dishes (Corning-Costar, Corning, NY, USA) $\left(2 \times 10^{4}\right.$ cells/well) and cultured for $16 \mathrm{~h}$. Then the cells were treated with different concentrations of nifuroxazide. After 48 and $72 \mathrm{~h}, 10 \mu \mathrm{l}$ of CCK8 was added to each well and the cells were incubated for another $4 \mathrm{~h}$, respectively. The viability effects were recorded using a multiwell microtiter plate reader (Thermo Fisher Scientific). Each experiment contained three wells and was repeated three times.

Wound healing assay. Cell migration activity was assessed using a wound healing assay. HepG2 cells $\left(3 \times 10^{5}\right.$ cells/well) were plated into 6-well flat-bottom dishes (Corning-Costar). After culturing for $16 \mathrm{~h}$, the initial gap was established using a micropipette tip and the gap length was measured. At the same time, nifuroxazide was added into the well at doses of $0.25,0.5,1,2$ and $4 \mu \mathrm{g} / \mathrm{ml}$. At $24 \mathrm{~h}$, and $48 \mathrm{~h}$ after cultured with nifuroxazide, the residual gap length was recorded, respectively. Each experiment contained three wells and was repeated three times.

Isolation of mouse bone-marrow-derived DCs. Mouse bonemarrow-derived DCs (BMDCs) were isolated from C57BL/6 mice as previously described $(18,19)$. Briefly, on day 0 , mice were sacrificed and bone marrow cells were sluiced out from the femurs and tibiae and added into ACK lysis buffer (Beyotime Biotechnology, Shanghai, China) to remove erythrocytes. Then the cells were cultured in a 6-well plate using RPMI 1640 medium supplemented with $20 \mathrm{ng} / \mathrm{ml}$ GM-CSF and $10 \%$ FBS. On day 2, the original medium was replaced with fresh medium including $20 \mathrm{ng} / \mathrm{ml} \mathrm{GM-CSF}$. On day 5 , half of the medium was replaced with fresh medium including $20 \mathrm{ng} / \mathrm{ml} \mathrm{IL-4}$ and $20 \mathrm{ng} / \mathrm{ml}$ GM-CSF. On day 7, the cells in plates were harvested. At this point, DCs mainly possessed the characteristic of immature DCs (iDC) and their purity was $\geq 85 \%$.

Preparation of the tumor cell lysate. TCL of $\mathrm{H} 22$ was prepared. In brief, cultured H22 cells were collected in phosphate buffered saline (PBS) buffer and lysed by a freeze-thaw cycle five times. Then, TCL were centrifuged for $10 \mathrm{~min}$ at 12,000 rpm and the supernatant was gathered with the tumor antigen and stored in a $-70^{\circ} \mathrm{C}$ refrigerator. Finally, the concentration of protein was evaluated using a BSA kit.

Preparation of TCL-pulsed DCs. iDCs $\left(3 \times 10^{6}\right)$ were loaded with TCL containing $100 \mu \mathrm{g}$ protein $/ \mathrm{ml}$ and incubated for $6 \mathrm{~h}$. Then the wells were super-induced by TNF- $\alpha$ at a concentration of $50 \mathrm{ng} / \mathrm{ml}$ and then cultured for another $72 \mathrm{~h}$. Finally, the DCs were harvested and the surface molecules of CD80 and CD86 were detected to determine whether DCs were mature.

Mouse experiments. In this study, male C57BL/6 mice were used to establish an orthotopically implanted HCC model and maintained at $22 \pm 2^{\circ} \mathrm{C}$ with a $12 \mathrm{~h}$ light/dark cycle. All mice had free access to food and water during the experiments. Briefly, two mice were injected subcutaneously with $1 \times 10^{6} \mathrm{H} 22$ cells. After 2 weeks, the tumors were isolated and cut into small pieces with an equal volume of $1 \mathrm{~mm}^{3}$. The C57/BL6 mice were anesthetized using pentobarbitone at dose of $70 \mathrm{mg} / \mathrm{kg}$ body weight. Then, the mice were laparotomized and the fragments of tumor tissue were thrusted into livers by forming a 3-mm-long hole.

After 7 days, the mice were randomly divided into four groups including PBS, nifuroxazide, TCL-pulsed DC and nifuroxazide combination with TCL-pulsed DC group. The mice in the PBS group were intraperitoneally injected with $100 \mu 1 \mathrm{PBS}$, mice in the nifuroxazide group were intraperitoneally injected with nifuroxazide at a dose of $200 \mu \mathrm{g}$ per mouse, mice in the TCL-loaded DC group were intravenously injected with DCs and mice in the combination treatment group were intraperitoneally injected with nifuroxazide at 


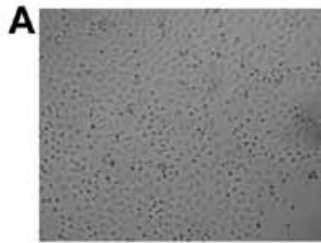

Medium

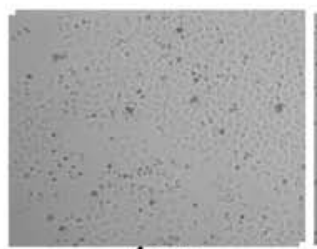

$4 \mu \mathrm{g}$

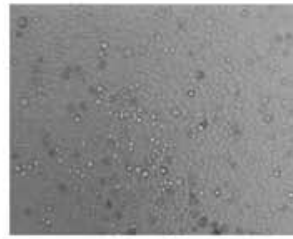

Medium

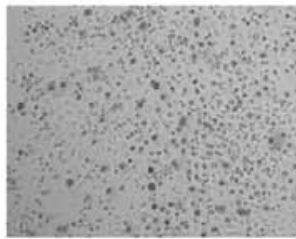

$4 \mu \mathrm{g}$

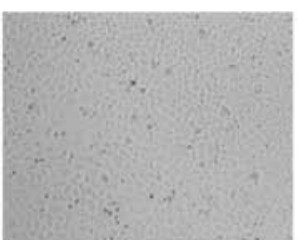

$0.5 \mu \mathrm{g}$

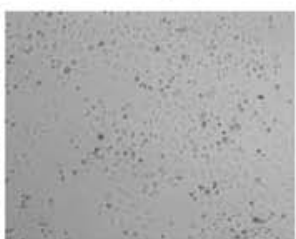

$8 \mu \mathrm{g}$

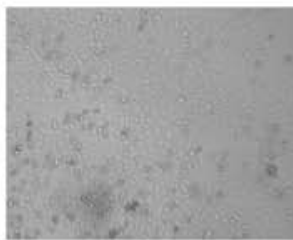

$0.5 \mu \mathrm{g}$

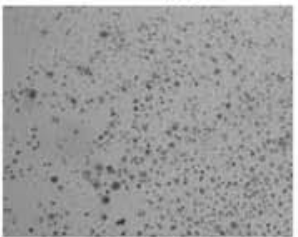

$8 \mu \mathrm{g}$

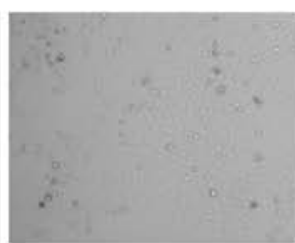

$1 \mu \mathrm{g}$

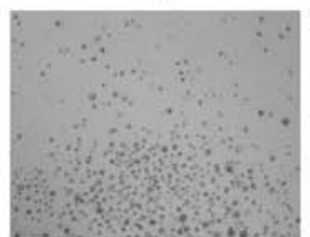

$16 \mu \mathrm{g}$

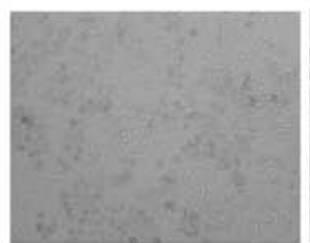

$1 \mu \mathrm{g}$

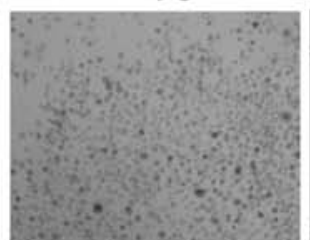

$16 \mu \mathrm{g}$
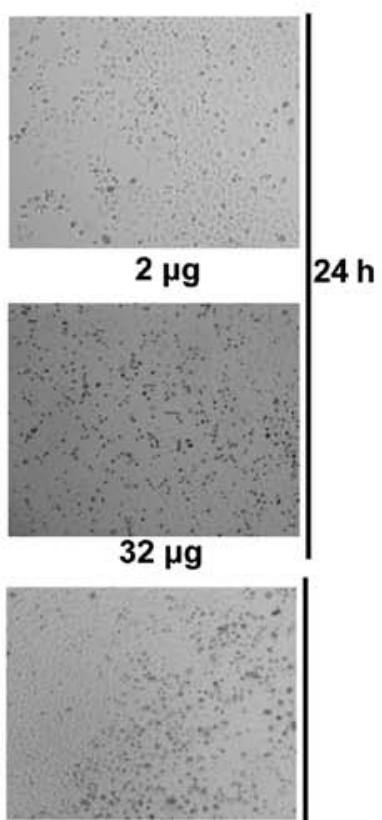

$2 \mu \mathrm{g}$

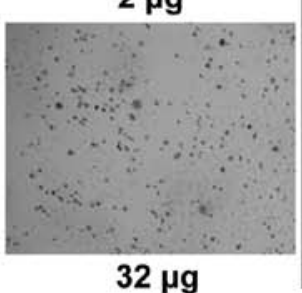

$48 \mathrm{~h}$

B

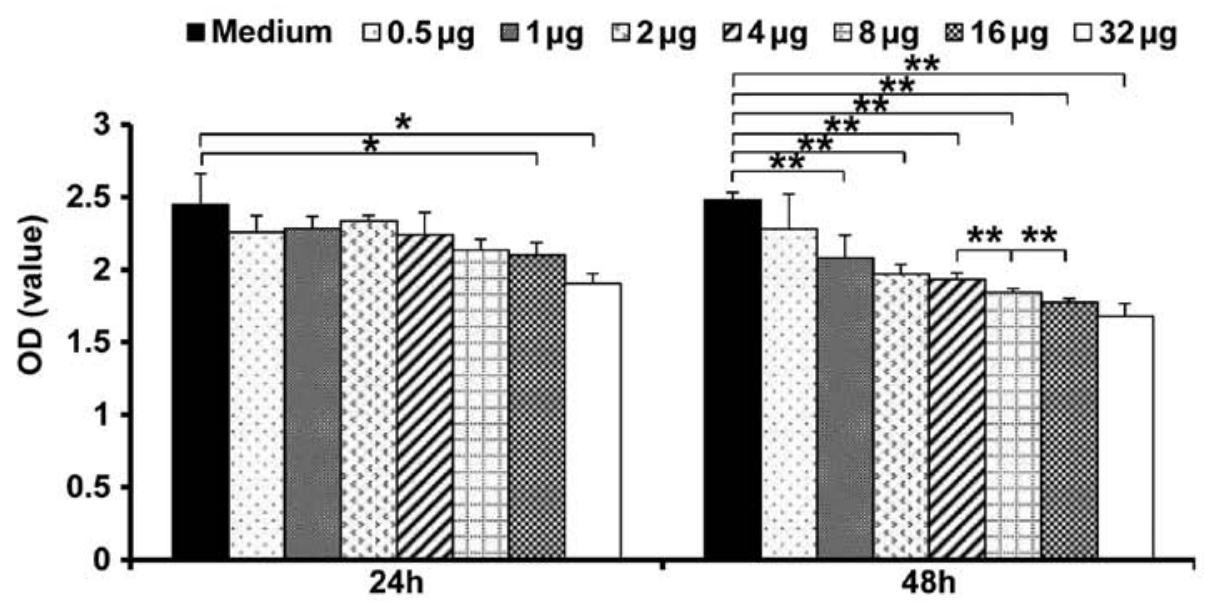

Figure 1. Effects of nifuroxazide on HCC cell viability. HepG2 cells were plated into 96 -well flat-bottom dishes (2x10 4 cells/well) and cultured for 16 h. Then the cells were treated with nifuroxazide at different concentrations $(0.50,1,2,4,8,16$ and $32 \mu \mathrm{g} / \mathrm{ml}$. After 24 and $48 \mathrm{~h}, 10 \mu 1$ of CCK8 was added to each well and incubated for $4 \mathrm{~h}$, respectively. Each experiment contained three wells and was repeated three times. (A) The killing effect of nifuroxazide on HepG2. (B) The optical density (OD) value of surviving cells. ${ }^{*} \mathrm{P}<0.05,{ }^{* *} \mathrm{P}<0.01$.

a dose of $200 \mu \mathrm{g}$ per mouse plus intravenously injection of DCs. Nifuroxazide was injected once daily and maintained for 7 days. TCL-loaded DCs were injected, respectively, on 7 and 14 days after tumor challenge. The survival rate was recorded each day and the tumor was weighed at 21 days after tumor challenge.

Immunohistochemistry assay. At 14 days after treatment, tumor tissues were fixed in $10 \%$ neutral formalin for $24 \mathrm{~h}$, and then the tissues were embedded in paraffin and cut into $5 \mu$ m-thick sections for next assay as previously described. To analyze the lymphocyte infiltration of tumor tissues, immunohistochemical analyses were carried out using antibodies against CD4and CD8 (Santa Cruz Biotechnology, Santa Cruz, CA, USA).

Flow cytometry assay. The ratios of CD4, CD8 and NK cells in splenocytes were analyzed using flow cytometry. Briefly, at 14 days after treatment, 3 mice from group were randomly sacrificed. The spleens were isolated and homogenized in RPIM-1640, and centrifuged at $2000 \mathrm{rpm}$ for $5 \mathrm{~min}$ at $4^{\circ} \mathrm{C}$. The precipitates were harvested and lysed the red blood cell using 


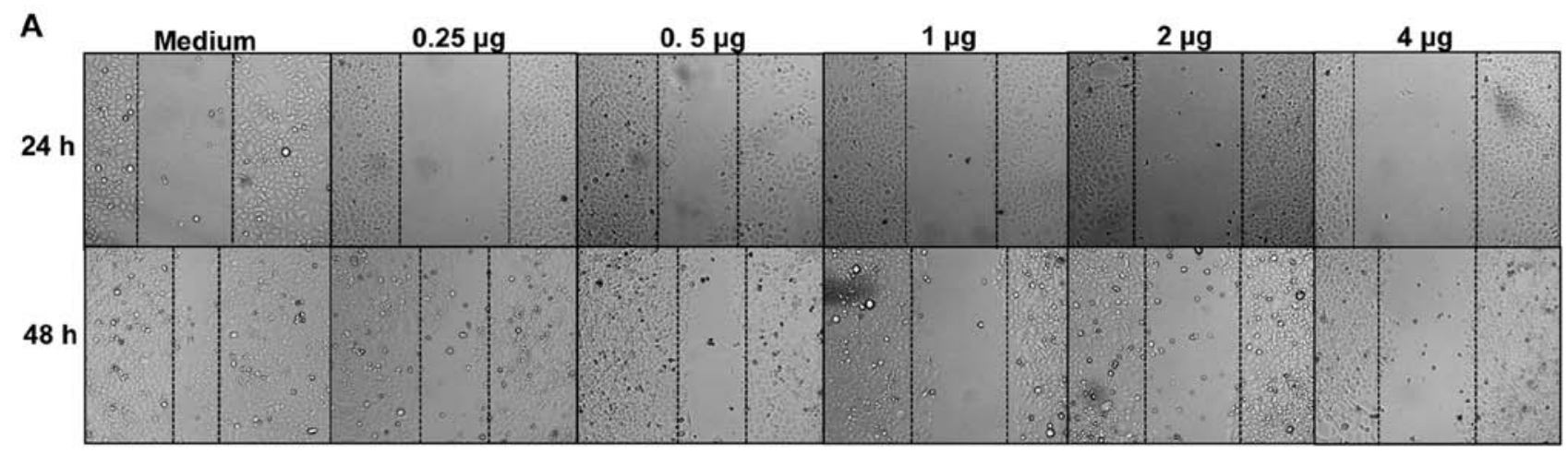

B

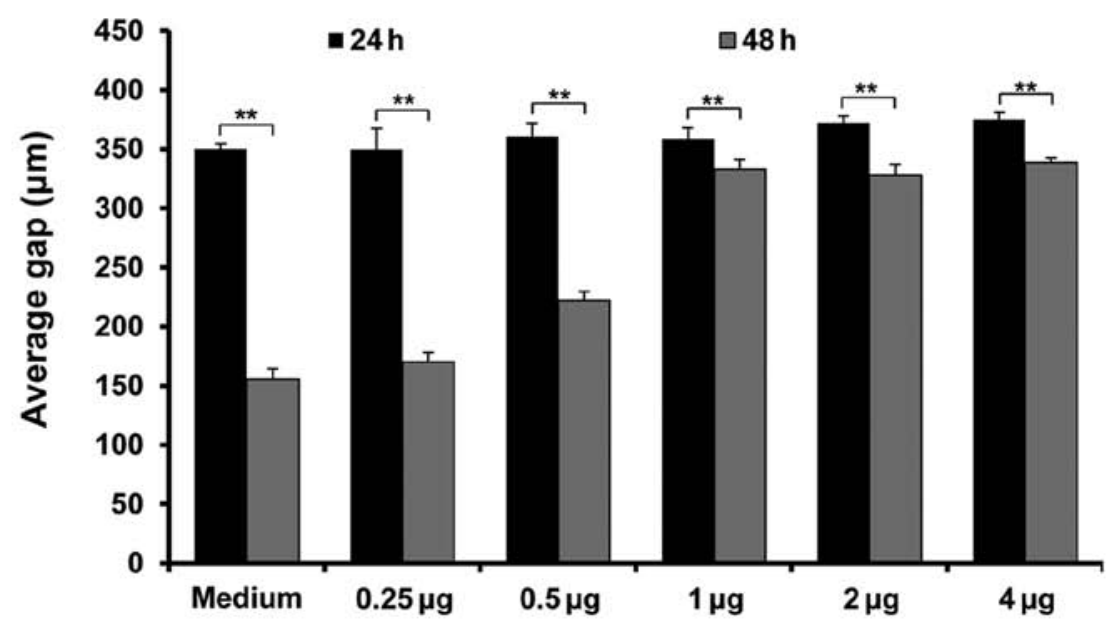

Figure 2. Effects of nifuroxazide on HCC cell migration. Cell migration activity was assessed using the wound healing assay. Nifuroxazide was added into the wells at the doses of $0.25,0.51,2$, and $4 \mu \mathrm{g} / \mathrm{ml}$. At 24 and $48 \mathrm{~h}$ after culturing with nifuroxazide, the residual gap length was recorded, respectively. Each experiment contained three wells and was repeated three times. (A) The effect of nifuroxazide on cell migration. (B) The mean gap statistics. ${ }^{*} \mathrm{P}<0.05$, ${ }^{* *} \mathrm{P}<0.01$.

ACK buffer. The cells were harvested and counted. Then, the splenocytes were incubated with the following antibodies: CD3-FITC, CD4-PE, CD8-APC and NK1.1-PE (BioLegend) at $4^{\circ} \mathrm{C}$ for $30 \mathrm{~min}$. Finally, the cells were washed and detected by flow cytometry. Staining score was made according to the standards of grading: 0 , no positive cells; 1, population of positive cells $<1 \%$; 2 , population of positive cells $>1 \%,<10 \%$; 3 , population of positive cells $>10 \%,<20 \%$; 4 , population of positive cells $>20 \%$.

Detection of cytokines. Mouse serum was separated at 21 days after tumor challenge. The samples were centrifuged at $6,000 \mathrm{rpm}$ for $10 \mathrm{~min}$ at $4^{\circ} \mathrm{C}$. The levels of interferon (IFN)- $\gamma$, TNF- $\alpha$ or vascular endothelial growth factor (VEGF) were determined using enzyme-linked immunosorbent assay (ELISA) kit (RayBiotech, Inc.) according to the manufacturer's directions.

Detection of protein expression. To analyze protein expression, tumor tissues were lysed using RIPA Lysis Buffer (Beyotime Institute of Biotechnology, Shanghai, China) and the expression of various proteins was detected by western blotting (WB) as previously described (20). The antibodies were against STAT3, p-STAT3, cleaved caspase-3, MMP2 and PARP. All the antibodies were purchased from cell signaling technology except the $\alpha$-tubulin, which was purchased from Sigma-Aldrich (St. Louis, MO, USA).
Statistical analysis. Data are shown as the mean \pm standard deviation (SD). The survival of mice in different groups was determined by the Kaplan-Meier test. Other data were determined by one-way ANOVA. All statistical analysis was performed using SPSS software and the statistical differences were considered at $\mathrm{P}<0.05$.

\section{Results}

Nifuroxazide inhibits hepatocellular carcinoma cell invasion and migration. HepG2 cells were treated with different concentrations $(0.5,1,2,4,8,16$ and $32 \mu \mathrm{g} / \mathrm{ml})$ of nifuroxazide to investigate its effect on HCCs. Cell proliferation was detected at 24 and $48 \mathrm{~h}$ post-treatment, respectively. The results showed that $24 \mathrm{~h}$ after treatment with nifuroxazide, the cell viability only was significantly inhibited at the concentration of $32 \mu \mathrm{g} / \mathrm{ml}$ compared with treatment of medium alone, while nifuroxazide inhibited cell viability at all tested concentration at $48 \mathrm{~h}$. These data suggested that nifuroxazide inhibited HepG2 cell viability time and concentration dependently. However, nifuroxazide at the doses of 16 and $32 \mu \mathrm{g} / \mathrm{ml}$ showed similar cell viability (Fig. 1).

Next, we investigated whether nifuroxazide could inhibit cell migration. As shown in Fig. 2, cell migration was significantly inhibited at $24 \mathrm{~h}$ after treatment with nifuroxazide at concentrations of 2 or $4 \mu \mathrm{g} / \mathrm{ml}$. Although nifuroxazide significantly inhibited cell migration at the concentrations of 

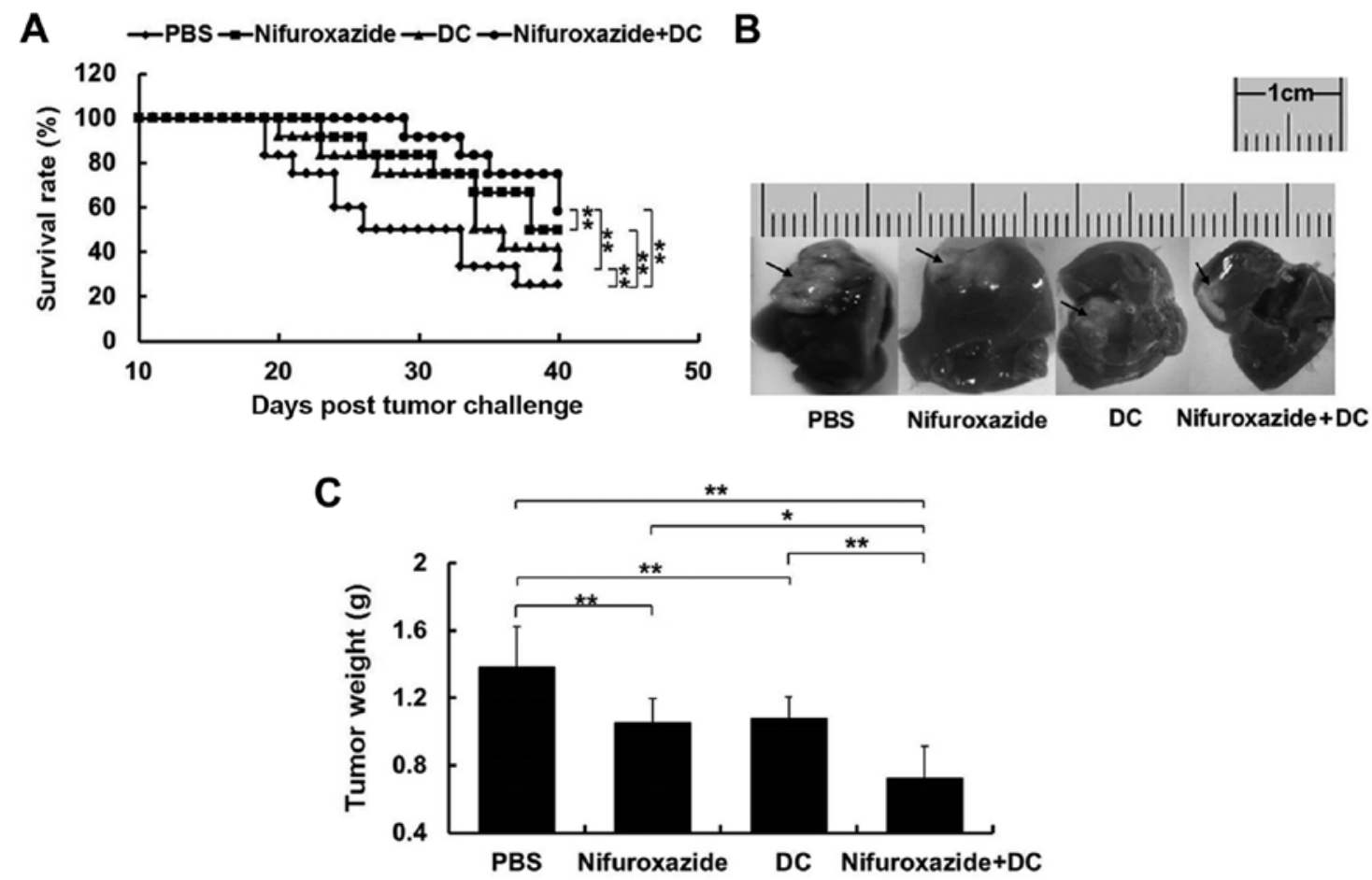

Figure 3. Combined application of nifuroxazide and TCL-loaded DC inhibited tumor growth and enhanced the survival. At day 7 after the orthotopically implanted HCC model was established, mice were randomly divided into four groups and treated with PBS, nifuroxazide, TCL-loaded DC or nifuroxazide combination with TCL-loaded DC, respectively. Survival was recorded and tumors were weighed at 21 days after tumor challenge. (A) The survival curve. (B) Size of tumors. (C) Tumor weight. Data are presented as mean \pm SD. ${ }^{*} \mathrm{P}<0.05,{ }^{* *} \mathrm{P}<0.01$.

$0.50,1,2$ and $4 \mu \mathrm{g} / \mathrm{ml}$, respectively, at $48 \mathrm{~h}$, nifuroxazide at the concentrations of 1,2 or $4 \mu \mathrm{g} / \mathrm{ml}$ had a similar effect on cell migration (Fig. 2).

Combined application of nifuroxazide and DC pulsed with TCL inhibits tumor growth and increases the survival rate of mice implanted with hepatocarcinoma. It has been demonstrated that nifuroxazide inhibited myeloid-derived suppressor cell (MDSCs) proliferation (17), thus we detected whether nifuroxazide could enhance the antitumor immune response of TCL-loaded DC in mice with implanted hepatocarcinoma. First, we detected the effect of different dose of nifuroxazide on mice with implanted hepatocarcinoma. We found that nifuroxazide at the dose of $200 \mu \mathrm{g}$ per mouse showed a preferable treatment effect compared with doses of 100 or $300 \mu \mathrm{g}$ per mouse (data not shown). Next, we detected whether nifuroxazide at $200 \mu \mathrm{g}$ per mouse could prompt the antitumor effect of TCL-loaded DC. The results showed that at 40 days post-tumor challenge, both of the survival rates of mice in the nifuroxazide group $(50 \%, \mathrm{n}=12)$ and DC group $(33.3 \%, \mathrm{n}=12)$ were significantly enhanced compared with the control group $(25 \%, n=12)$. Furthermore, the survival rate of mice in the combination treatment group was highest $(58.3 \%, \mathrm{n}=12)$ compared with the nifuroxazide group or DC group (Fig. 3A).

To further compare the antitumor effect of the combined application of nifuroxazide and TCL-loaded DC, we detected the tumor weight of mice at 21 days after tumor challenge. As shown in Fig. 3B and C, though the tumor growth was significantly inhibited in mice treated with nifuroxazide or TCL-loaded DC, the combined application with nifuroxazide and TCL-loaded DC had a more potent effect on inhibiting tumor growth.

Combined application of nifuroxazide and TCL-loaded DC increases lymphocyte infiltration in tumor tissues. Next, we detected $\mathrm{CD}^{+}$and $\mathrm{CD}^{+} \mathrm{T}$ lymphocyte infiltration in tumor tissues at 14 days post-tumor-bearing by immunohistochemistry. As shown in Fig. 4, treatment with nifuroxazide or TCL-loaded DC increased the amount of $\mathrm{CD}^{+}$and $\mathrm{CD} 8^{+}$ $\mathrm{T}$ lymphocyte infiltration in tumor tissues compared with control group, respectively. Furthermore, the combination treatment resulted in the greatest amount of lymphocyte infiltration in tumor tissues (Fig. 4).

Combined application of nifuroxazide and TCL-loaded DC elevated the immune cell response in spleen. Spleen, as the largest peripheral immune organ, is known to play an irreplaceable role in antitumor immunity. Thus, we assumed that the difference of lymphocyte infiltration in tumor tissues was related to the percentage change of lymphocyte numbers in the spleen. Excitedly, application of nifuroxazide or TCL-loaded DC significantly increased the numbers of $\mathrm{CD}^{+}$and $\mathrm{CD} 8^{+}$ $\mathrm{T}$ lymphocytes in the spleen. Importantly, the combination treatment induced the greatest number of lymphocytes in the spleen, especially $\mathrm{CD}^{+} \mathrm{T}$ lymphocytes compared with the control group, and nifuroxazide or TCL-loaded DC group (Fig. 5A).

In addition, we determined the number of NK cells, which play an important effect on fighting tumors. A similar situation was observed as for T lymphocytes in the spleen. The combination treatment led to the most marked observable increment of NK cells in the spleen (Fig. 5B). 


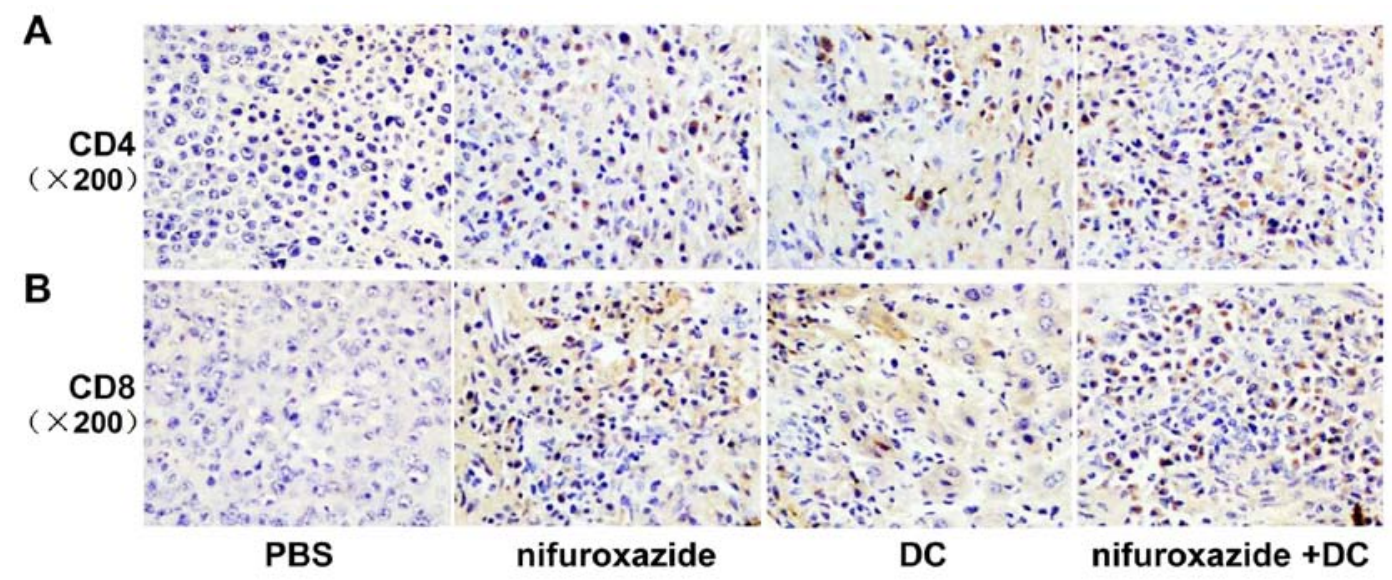

C

-PBS $\square$ DC $\square$ nifuroxazide $\square$ nifuroxazide+DC

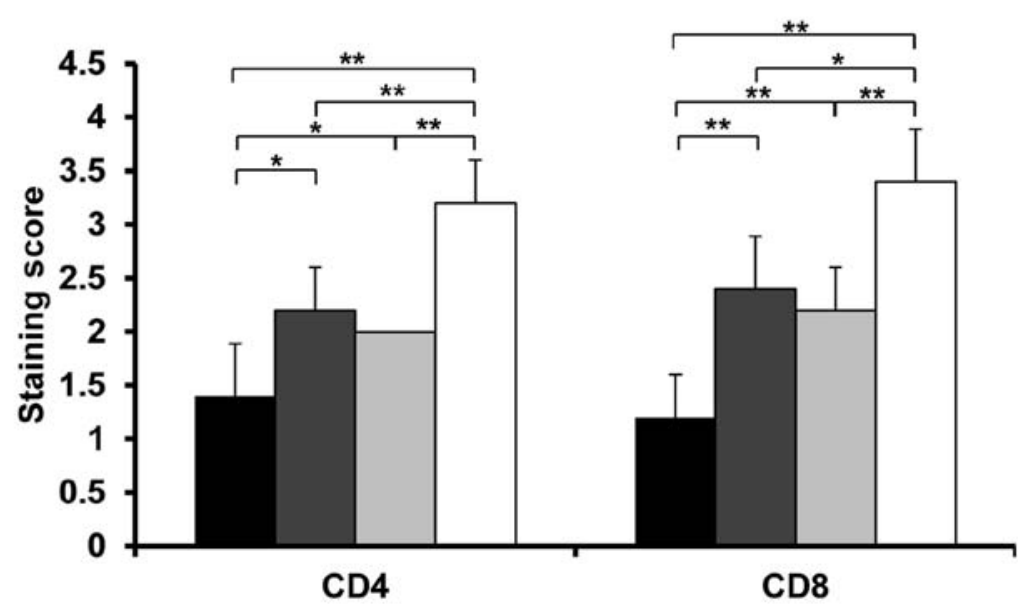

Figure 4. Combined application of nifuroxazide and TCL-loaded DC increased lymphocyte infiltration in tumor tissues. At 21 days after tumor challenge, $\mathrm{CD}^{+}(\mathrm{A})$ and $\mathrm{CD}^{+}(\mathrm{B}) \mathrm{T}$ cell infiltration were detected using the immunohistochemical analysis. (C) The statistical analysis for immunohistochemistry assay. ${ }^{*} \mathrm{P}<0.05,{ }^{* *} \mathrm{P}<0.01$.

Combined application of nifuroxazide and TCL-loaded DC influences the concentration of cytokines in serum. The cytokines could play a role of eliciting beneficial antitumor effects. Thus, levels of IFN- $\gamma$, TNF- $\alpha$ and VEGF in sera were detected by ELISA kits. The results showed that the application of nifuroxazide or TCL-loaded DC increased the levels of IFN- $\gamma$ and TNF- $\alpha$, but did not influence the concentration of VEGF. The combined application of nifuroxazide and TCL-loaded DC not only significantly increased the levels of IFN- $\gamma$ and TNF- $\alpha$, but also inhibited the release of VEGF compared with the nifuroxazide or TCL-loaded DC group (Fig. 5C-E).

Combined application of nifuroxazide and TCL-loaded DC influences the protein expression in tumor tissues. Many proteins participate in the nascence and development of tumor, therefore, we investigated the expression of some classical proteins related to proliferation, apoptosis and migration in tumor tissues. As shown in Fig. 6, the combined application of nifuroxazide and TCL-loaded DC significantly inhibited the expression of matrix metalloproteinase 2 (MMP-2) that is related with the tumor development and the formed tumor microvasculature, increased the expression of casepase 3 that is known to relate with the tumor cell apoptosis, and reduced the level of poly ADP-ribose polymerase (PARP) which is a substrate incised by caspase protein. In addition, nifuroxazide has been proven to inhibit the STAT3 expression, so we also detected the influence of the combined application of nifuroxazide and TCL-loaded DC on STAT3 expression in tumor tissues. The result showed that the STAT3 expression did not significantly lessen in the nifuroxazide group and combined group, however the phosphorylation STAT3 was obviously inhibited.

\section{Discussion}

HCC is a frequent human malignancy globally with a poor prognosis due to the absence of effective treatment methods. The antitumor immune responses are often impaired because of the presentation of immunosuppressive factors in the microenvironment of tumor tissues (21). Thus, improving antitumor immune responses would be a useful method to treat HCC. DCs, known as a professional antigen-presenting cells, play an important role in $\mathrm{T}$ cell activation. However, in the body of tumor patients exist a large number of immature DC that could not provide the costimulation signals to help $\mathrm{T}$ cell development and proliferation (22). Activation of STAT3 has been proved to inhibit the function of immune cells including 
A

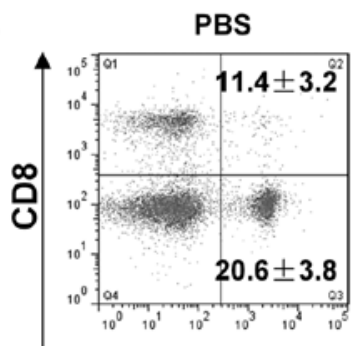

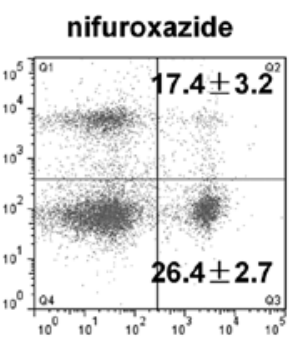

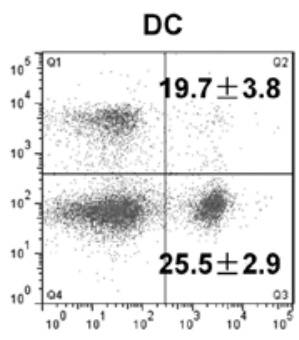

nifuroxazide $+D C$

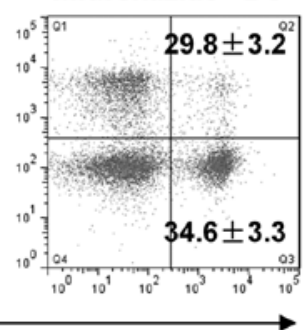

CD4

B
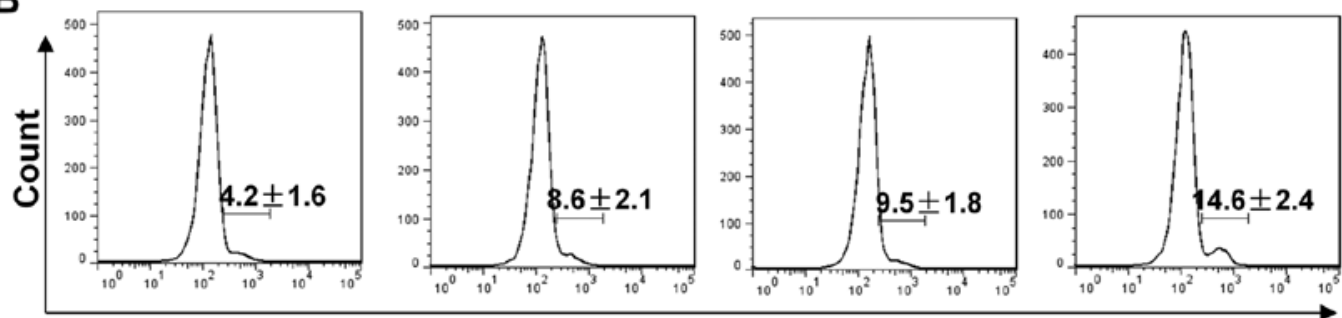

\section{NK1.1}

C

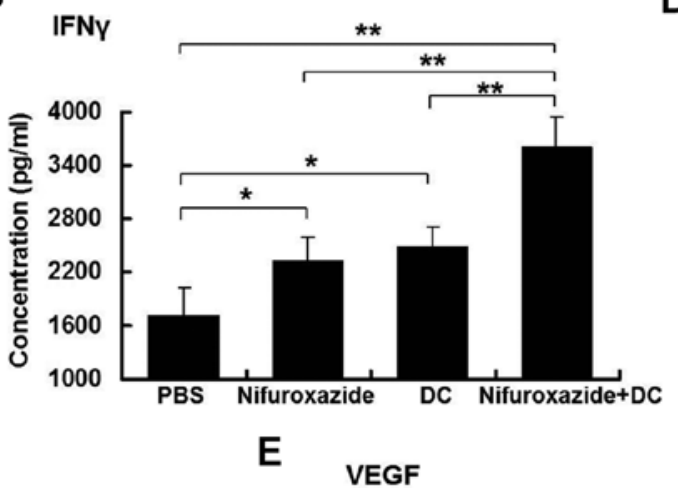

D TNFa
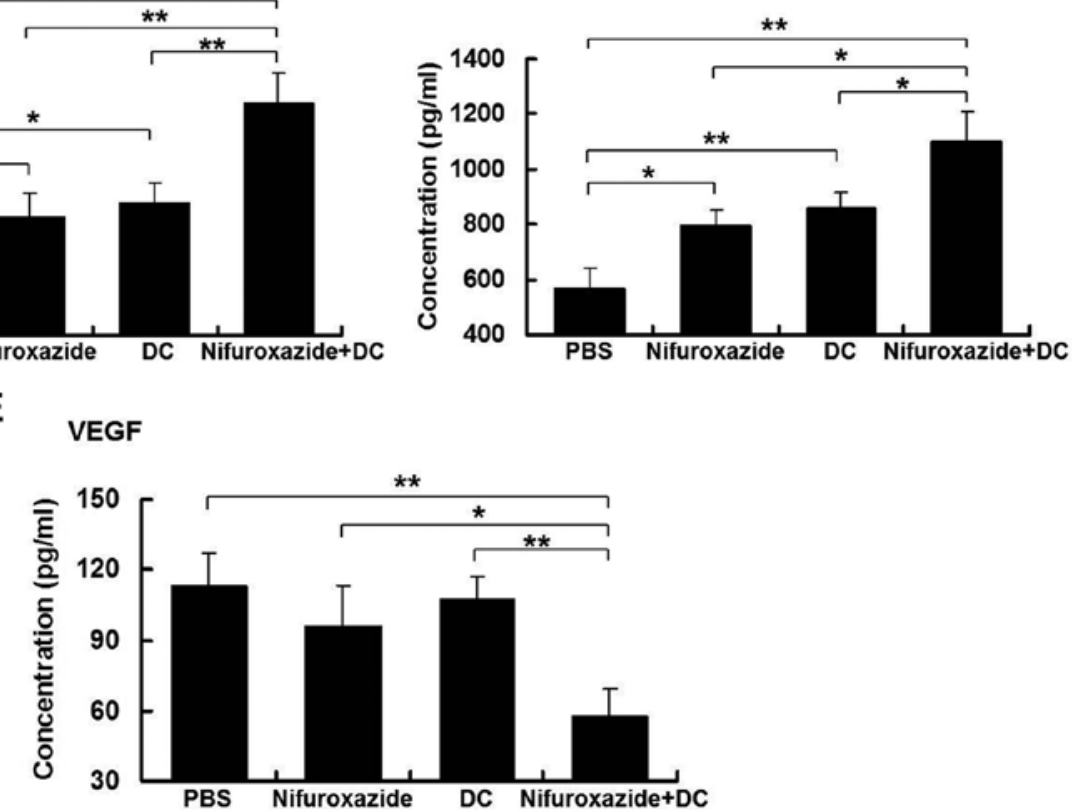

Figure 5. Combined application of nifuroxazide and TCL-loaded DC increased the ratio of CD4 $4^{+}$, CD $8^{+} \mathrm{T}$ cells and $\mathrm{NK}$ cells in spleens and raised the concentration of cytokines. At 21 days after tumor challenge, the splenocytes were isolated and the ratios of $\mathrm{CD}^{+}$, and $\mathrm{CD} 8^{+} \mathrm{T}$ cells as well as $\mathrm{NK}$ cells were detected using flow cytometry. The concentrations of cytokines in serum were detected using ELISA kits. (A) The ratios of CD4 ${ }^{+}$and CD ${ }^{+} \mathrm{T}$ cells in spleens. (B) The number of NK cells in spleens. Data are presented as the mean \pm SD. (C-E) The concentration of IFN- $\gamma$, TNF- $\alpha$ and VEGF. Data are presented as the mean \pm SD. ${ }^{*} \mathrm{P}<0.05,{ }^{* *} \mathrm{P}<0.01$.

DCs, NK cells, macrophages and T cells (23-26). Furthermore, the activation of STAT3 also played a key role in the progress of HCC $(27,28)$. In a previous study, nifuroxazide, a STAT3 inhibitor, induced tumor cell apoptosis, suppressed the tumor migration and reduced the MDSC infiltration in the lungs of mice in a breast cancer model (17). Furthermore, because single treatment strategy does not have satisfactory effect, combination treatments are increasingly studied. Thus, in this study, we showed that combined application of nifuroxazide and TCL-loaded DC significantly enhanced the survival rate, and inhibited the tumor growth in mice with orthotopicallyimplanted hepatocarcinomas. Importantly, treatment with nifuroxazide and TCL-loaded DC improved the antitumor immune response by increasing the number of $\mathrm{T}$ cells in spleen and enhancing $\mathrm{T}$ cell infiltration in tumor tissues.

$\mathrm{CD}^{+} \mathrm{T}$ and NK cells, which have the major antitumor effects in vivo, the function, included directly killing the tumor cells and indirectly damaging the tumor cells by secreting cytokines. It was shown that DC-based vaccine enhanced T cell-mediated cytotoxicity and cytokine secretion $(29,30)$. However, TCL-loaded DC might play a dual role by inducing low antitumor tumor responses and attenuating $\mathrm{T}$ cell immune responses (31). In addition, the activation of STAT3 has been demonstrated not only to suppress the DC maturity, but also 
A

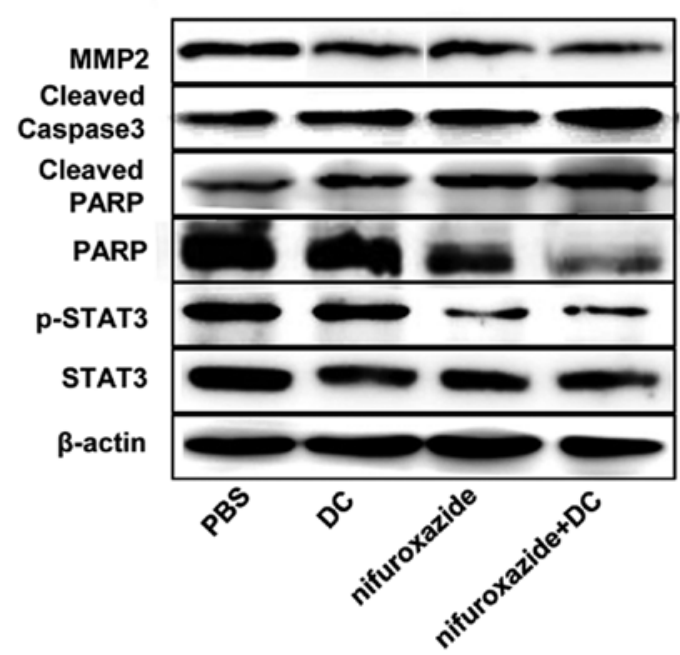

B

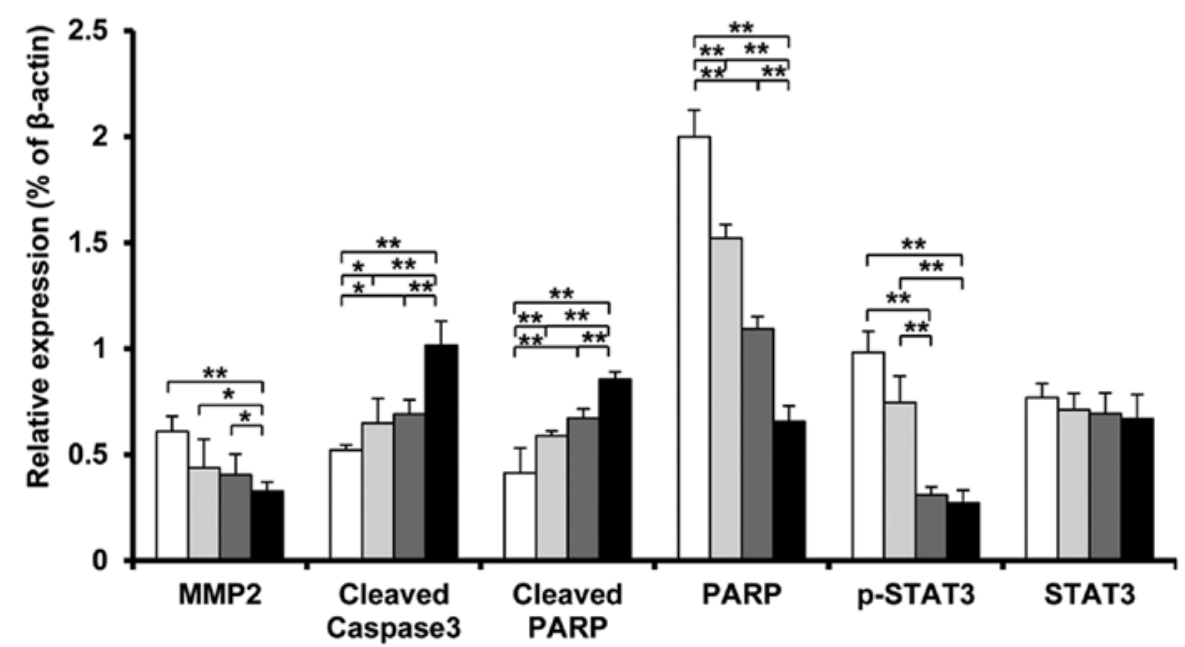

Figure 6. Combined application of nifuroxazide and TCL-loaded DC influences the expression of apoptosis and migration related proteins. At 21 days after tumor challenge, 3 mice in each group were randomly sacrificed and the tumor tissues were isolated. The relative expression of proteins in tumor tissues were detected by western blotting. (A) The western blotting results of each protein in every group. (B) The statistical analysis. ${ }^{*} \mathrm{P}<0.05,{ }^{* *} \mathrm{P}<0.01$.

to inhibit the proliferation of T lymphocytes, the infiltration of NK cells and the antitumor immune response (23-26). In our experiments, treatment with nifuroxazide or TCL-loaded DC increased the $\mathrm{T}$ lymphocyte infiltration in tumor tissues and the ratio of $\mathrm{CD}^{+} \mathrm{T}$ and $\mathrm{NK}$ cells in the spleen. Importantly, combination application of nifuroxazide and TCL-loaded DC had the strongest effect on the raising lymphocyte infiltration and the proliferation of $\mathrm{T}$ lymphocytes and NK cells. This might be related to the inhibition of p-STAT3 expression. We found that combined application of nifuroxazide and TCL-loaded DC significantly inhibited the expression of p-STAT3 compared with PBS group and nifuroxazide group. Inhibition of the expression of STAT3 increased the T cell infiltration and proliferation (32). Moreover, application of nifuroxazide inhibited the proliferation of MDSC that had an immunosuppressive effect on antitumor responses (17). This might be the method to strengthen the antitumor immune response of TCL-loaded DC by combination application with nifuroxazide.

Furthermore, several immune cells were shown to be involved in antitumor response through secreting some cytokines including IFN- $\gamma$ and TNF- $\alpha$ (33-35). So the increased number of T lymphocytes and NK cells would lead to higher level of cytokines in the serum. Similar with the antitumor effect, our results showed the combination application of nifuroxazide and TCL-loaded DC significantly raised the concentration of IFN- $\gamma$ and TNF- $\alpha$. In addition, VEGF, secreted by tumor cells, induced the hyperplasia of tumor vessels, facilitated the proliferation of tumor cells, and inhibited the tumor apoptosis $(36,37)$. Noteworthy, we found that treatment with nifuroxazide or TCL-loaded DC did not significantly inhibit the level of VEGF, but the combination application of nifuroxazide and TCL-loaded DC had the maximum inhibition effect on the release of VEGF compared with nifuroxazide or TCL-loaded DC group. Since STAT3 signal could promote angiogenesis, we considered that this finding might be related to the lowest expression level of p-STAT3 (38), and the lowest tumor weight.

In addition, the activation of STAT3 signals also promoted tumorigenesis, migration and inhibited cell apoptosis by dysregulating the expression of key proteins including caspase 3, bcl2, MMP2 and MMP9 (39-42). In this study, combination therapy showed a significant inhibitory effect on 
the expression of MMP2, which promotes tumor migration and progress, and increased the expression of caspase 3, an apoptosis-related protein (43). Apoptosis participates in pathogenesis and progression of cancer. Inducing the expression of apoptosis-related proteins might have antitumor effects and inhibit tumor growth $(36,44)$.

In summary, we demonstrated that combination treatment of nifuroxazide and TCL-loaded DC significantly inhibited tumor growth and prompted the antitumor immune responses in a mouse model of orthotopically-implanted hepatocarcinoma. Nifuroxazide and TCL-loaded DC might be a novel method for treatment of HCC, but further in-depth research is still needed.

\section{Acknowledgements}

This study was supported by the National Natural Science Foundation of China (no. 81301947 and 81300442), the Scientific Research Fund of Xinxiang Medical University (no. 2013QN112), the Doctor Launch Fund of Xinxiang Medical University (no. 505016), the platform of collaborative innovation center of Molecular Diagnosis and Laboratory Medicine- Momentous Science and Technology Project of Xinxiang in 2014 and Natural Science Fund for colleges and universities in Jiangsu Province (no. 13KJB320028).

\section{References}

1. Torre LA, Bray F, Siegel RL, Ferlay J, Lortet-Tieulent J and Jemal A: Global cancer statistics, 2012. CA Cancer J Clin 65 87-108, 2015.

2. Llovet JM: Treatment of hepatocellular carcinoma. Curr Treat Options Gastroenterol 7: 431-441, 2004.

3. Bruix J, Reig M and Sherman M: Evidence-based diagnosis, staging, and treatment of patients with hepatocellular carcinoma Gastroenterology 150: 835-853, 2016.

4. Zhao F, Korangy F and Greten TF: Cellular immune suppressor mechanisms in patients with hepatocellular carcinoma. Dig Dis 30: 477-482, 2012

5. Harding JJ, El Dika I and Abou-Alfa GK: Immunotherapy in hepatocellular carcinoma: Primed to make a difference? Cancer 122: 367-377, 2016.

6. Steinman RM and Cohn ZA: Pillars Article: Identification of a novel cell type in peripheral lymphoid organs of mice. I. Morphology, quantitation, tissue distribution. J. Exp. Med.1973. 137: 1142-1162. J Immunol 178: 5-25, 2007.

7. Sun K, Wang L and Zhang Y: Dendritic cell as therapeutic vaccines against tumors and its role in therapy for hepatocellular carcinoma. Cell Mol Immunol 3: 197-203, 2006.

8. Ge C, Xing Y, Wang Q, Xiao W, Lu Y, Hu X, Gao Z, Xu M, Ma Y, Cao R, et al: Improved efficacy of therapeutic vaccination with dendritic cells pulsed with tumor cell lysate against hepatocellular carcinoma by introduction of 2 tandem repeats of microbial HSP70 peptide epitope 407-426 and OK-432. Int Immunopharmacol 11: 2200-2207, 2011.

9. Lee WC, Wang HC, Hung CF, Huang PF, Lia CR and Chen MF: Vaccination of advanced hepatocellular carcinoma patients with tumor lysate-pulsed dendritic cells: A clinical trial. J Immunother 28: 496-504, 2005.

10. Lee JH, Lee Y, Lee M, Heo MK, Song JS, Kim KH, Lee H, Yi NJ, Lee KW, Suh KS, et al: A phase I/IIa study of adjuvant immunotherapy with tumour antigen-pulsed dendritic cells in patients with hepatocellular carcinoma. Br J Cancer 113: 1666-1676, 2015.

11. Sun X, Zhang J, Wang L and Tian Z: Growth inhibition of human hepatocellular carcinoma cells by blocking STAT3 activation with decoy-ODN. Cancer Lett 262: 201-213, 2008.

12. Sui Q, Zhang J, Sun X, Zhang C, Han Q and Tian Z: NK cells are the crucial antitumor mediators when STAT3-mediated immunosuppression is blocked in hepatocellular carcinoma. J Immunol 193: 2016-2023, 2014.
13. Murone M, Vaslin Chessex A, Attinger A, Ramachandra R, Shetty SJ, Daginakatte G, Sengupta S, Marappan S, Dhodheri S, Rigotti S, et al: Debio 0617B inhibits growth of STAT3-driven solid tumors through combined inhibition of JAK, SRC, and class III/V receptor tyrosine kinases. Mol Cancer Ther 15: 2334-2343, 2016

14. Hillmer EJ, Zhang H, Li HS and Watowich SS: STAT3 signaling in immunity. Cytokine Growth Factor Rev 31: 1-15, 2016.

15. Yu H, Kortylewski M and Pardoll D: Crosstalk between cancer and immune cells: Role of STAT3 in the tumour microenvironment. Nat Rev Immunol 7: 41-51, 2007.

16. Nelson EA, Walker SR, Kepich A, Gashin LB, Hideshima T, Ikeda H, Chauhan D, Anderson KC and Frank DA: Nifuroxazide inhibits survival of multiple myeloma cells by directly inhibiting STAT3. Blood 112: 5095-5102, 2008.

17. Yang F, Hu M, Lei Q, Xia Y, Zhu Y, Song X, Li Y, Jie H, Liu C, Xiong $\mathrm{Y}$, et al: Nifuroxazide induces apoptosis and impairs pulmonary metastasis in breast cancer model. Cell Death Dis 6: e1701, 2015

18. Chang WT, Chen HM, Yin SY, Chen YH, Wen CC, Wei WC, Lai P, Wang CH and Yang NS: Specific Dioscorea phytoextracts enhance potency of TCL-loaded DC-based cancer vaccines. Evid Based Complement Alternat Med 2013: 932040, 2013.

19. Yin SY, Wang CY and Yang NS: Interleukin-4 enhances trafficking and functional activities of GM-CSF-stimulated mouse myeloid-derived dendritic cells at late differentiation stage. Exp Cell Res 317: 2210-2221, 2011.

20. Nefedova Y, Cheng P, Gilkes D, Blaskovich M, Beg AA, Sebti SM and Gabrilovich DI: Activation of dendritic cells via inhibition of Jak2/STAT3 signaling. J Immunol 175: 4338-4346, 2005.

21. Yang JD, Nakamura I and Roberts LR: The tumor microenvironment in hepatocellular carcinoma: Current status and therapeutic targets. Semin Cancer Biol 21: 35-43, 2011.

22. Kalinski P: Dendritic cells in immunotherapy of established cancer: Roles of signals 1, 2, 3 and 4. Curr Opin Investig Drugs 10: 526-535, 2009

23. Wang T, Niu G, Kortylewski M, Burdelya L, Shain K, Zhang S, Bhattacharya R, Gabrilovich D, Heller R, Coppola D, et al: Regulation of the innate and adaptive immune responses by Stat-3 signaling in tumor cells. Nat Med 10: 48-54, 2004.

24. Cacalano NA: Regulation of natural killer cell function by STAT3. Front Immunol 7: 128, 2016.

25. Hollander L, Guo X, Velazquez H, Chang J, Safirstein R, Kluger H, Cha C and Desir GV: Renalase expression by melanoma and tumor-associated macrophages promotes tumor growth through a STAT3-mediated mechanism. Cancer Res 76: 3884-3894, 2016.

26. Yue C, Shen S, Deng J, Priceman SJ, Li W, Huang A and Yu H: STAT3 in $\mathrm{CD}^{+} \mathrm{T}$ cells inhibits their tumor accumulation by downregulating CXCR3/CXCL10 axis. Cancer Immunol Res 3: 864-870, 2015.

27. Ghoshal S, Fuchs BC and Tanabe KK: STAT3 is a key transcriptional regulator of cancer stem cell marker CD133 in HCC. Hepatobiliary Surg Nutr 5: 201-203, 2016.

28. Zheng X, Xu M, Yao B, Wang C, Jia Y and Liu Q: IL-6/STAT3 axis initiated CAFs via up-regulating TIMP-1 which was attenuated by acetylation of STAT3 induced by PCAF in HCC microenvironment. Cell Signal 28: 1314-1324, 2016.

29. Tang Q, Jiang J and Liu J: CCR5 blockade suppresses melanoma development through inhibition of IL-6-Stat 3 pathway via upregulation of SOCS3. Inflammation 38: 2049-2056, 2015.

30. Delirezh N, Moazzeni SM, Shokri F, Shokrgozar MA, Atri M and Kokhaei P: Autologous dendritic cells loaded with apoptotic tumor cells induce $\mathrm{T}$ cell-mediated immune responses against breast cancer in vitro. Cell Immunol 257: 23-31, 2009.

31. Yang DH, Park JS, Jin CJ, Kang HK, Nam JH, Rhee JH, Kim YK, Chung SY, Choi SJ, Kim HJ, et al: The dysfunction and abnormal signaling pathway of dendritic cells loaded by tumor antigen can be overcome by neutralizing VEGF in multiple myeloma. Leuk Res 33: 665-670, 2009.

32. Jia H, Li Y, Zhao T, Li X, Hu J, Yin D, Guo B, Kopecko DJ, Zhao X, Zhang L, et al: Antitumor effects of Stat3-siRNA and endostatin combined therapies, delivered by attenuated Salmonella, on orthotopically implanted hepatocarcinoma. Cancer Immunol Immunother 61: 1977-1987, 2012.

33. McMichael EL, Jaime-Ramirez AC, Guenterberg KD, Luedke E, Atwal LS, Campbell AR, Hu Z, Tatum AS, Kondadasula SV, Mo X, et al: IL-21 enhances natural killer cell response to cetuximab-coated pancreatic tumor cells. Clin Cancer Res 23: 489-502, 2017. 
34. Iraolagoitia XL, Spallanzani RG, Torres NI, Araya RE, Ziblat A, Domaica CI, Sierra JM, Nuñez SY, Secchiari F, Gajewski TF, et al: NK cells restrain spontaneous antitumor $\mathrm{CD}^{+} \mathrm{T}$ cell priming through PD-1/PD-L1 interactions with dendritic cells. J Immunol 197: 953-961, 2016.

35. Kozlowska AK, Tseng HC, Kaur K, Topchyan P, Inagaki A, Bui VT, Kasahara N, Cacalano N and Jewett A: Resistance to cytotoxicity and sustained release of interleukin- 6 and interleukin- 8 in the presence of decreased interferon- $\gamma$ after differentiation of glioblastoma by human natural killer cells. Cancer Immunol Immunother 65: 1085-1097, 2016.

36. Xia Y, Song X, Li D, Ye T, Xu Y, Lin H, Meng N, Li G, Deng S, Zhang S, et al: YLT192, a novel, orally active bioavailable inhibitor of VEGFR2 signaling with potent antiangiogenic activity and antitumor efficacy in preclinical models. Sci Rep 4: 6031, 2014

37. Ferrara N: VEGF and the quest for tumour angiogenesis factors. Nat Rev Cancer 2: 795-803, 2002.

38. Dong W, Xian Y, Yuan W, Huifeng Z, Tao W, Zhiqiang L, Shan F, Ya F, Hongli W, Jinghuan W, et al: Catalpol stimulates VEGF production via the JAK2/STAT3 pathway to improve angiogenesis in rats' stroke model. J Ethnopharmacol 191: 169-179, 2016.
39. Alvarez JV, Febbo PG, Ramaswamy S, Loda M, Richardson A and Frank DA: Identification of a genetic signature of activated signal transducer and activator of transcription 3 in human tumors. Cancer Res 65: 5054-5062, 2005.

40. Hsieh FC, Cheng G and Lin J: Evaluation of potential Stat3regulated genes in human breast cancer. Biochem Biophys Res Commun 335: 292-299, 2005.

41. Miklossy G, Hilliard TS and Turkson J: Therapeutic modulators of STAT signalling for human diseases. Nat Rev Drug Discov 12: 611-629, 2013.

42. Walker SR, Xiang M and Frank DA: Distinct roles of STAT3 and STAT5 in the pathogenesis and targeted therapy of breast cancer. Mol Cell Endocrinol 382: 616-621, 2014.

43. Cheung TH, Chung TK, Lo KW, Yu MY, Krajewski S, Reed JC and Wong YF: Apotosis-related proteins in cervical intraepithelial neoplasia and squamous cell carcinoma of the cervix. Gynecol Oncol 86: 14-18, 2002.

44. Hunter AM, LaCasse EC and Korneluk RG: The inhibitors of apoptosis (IAPs) as cancer targets. Apoptosis 12: 1543-1568, 2007. 